\title{
Formation and properties of stannate conversion coatings on AZ61 magnesium alloys
}

\author{
C.S. Lin ${ }^{a, *}$, H.C. Lin ${ }^{a}$, K.M. Lin ${ }^{b}$, W.C. Lai ${ }^{b}$ \\ a Department of Materials Science and Engineering, National Taiwan University, \\ 1, Roosevelt Road, Section 4, Taipei 106, Taiwan \\ ${ }^{\mathrm{b}}$ Department of Materials Science and Engineering, Feng Chia University, Taichung 407, Taiwan
}

Received 20 January 2004; accepted 6 November 2004

Available online 19 February 2005

\begin{abstract}
The effects of solution composition and temperature on the microstructure and corrosion resistance of stannate conversion coatings on AZ61 magnesium alloys were investigated. The conversion coating consisted of a porous layer as under layer intimately contacted with the magnesium plate and a hemispherical particle layer as major overlay formed right on top of the porous layer. During the coalescence of the hemispherical particles to form a complete coating on the magnesium alloy, some sites of discontinuity inevitably left and determined the corrosion resistance of the coating evaluated using a salt spray test. Increasing bath stannate ion concentration and lowering bath $\mathrm{pH}$ increased the population density of the hemispherical particles whose size was accordingly reduced. The corrosion resistance of the conversion coating was improved with finer particles, which were preferably formed at less alkaline solution with higher stannate ion contents. Furthermore, the conditions favoring the formation of finer particles also reduced the immersion time necessary for producing the conversion coating with optimal corrosion resistance.
\end{abstract}

(c) 2005 Elsevier Ltd. All rights reserved.

Keywords: AZ61 magnesium alloys; Stannate conversion coating; Salt spray test; Corrosion resistance

\footnotetext{
* Corresponding author. Tel.: +886 2 33665240; fax: +886 23634562.

E-mail address: csclin@ntu.edu.tw (C.S. Lin).
} 


\section{Introduction}

In light of their low density and high specific strength and stiffness, magnesium alloys are extensively used in electric appliances and structural components $[1,2]$. However, most of the magnesium alloys are relatively reactive and tend to suffer severe corrosion during service. Several surface modification treatments are thus performed to enhance the corrosion resistance of magnesium alloys, including anodizing [3-7], conversion coatings [8-15], electroless nickel plating [16], electrodeposition of nickel or polymer [17], PVD of high-purity magnesium [18], and nitrogen ion implantation $[19,20]$. Among the various treatments, the chemical conversion coating technique is known as a process of relatively-low cost and ease in operation, especially the chromate conversion coating, which has received extensive attention because of the excellent corrosion-resistant films and the simplicity in the coating process. However, the toxicity of hexavalent chromium has imposed a strict limitation on the use of the chromate conversion coating. Several non-chromate solutions are thus developed, such as phosphate, stannate, rare earth salt and phosphate/permanganate solutions [2,3,9-15].

The properties of conversion coatings are closely related to their microstructure and compositions, which in turn, strongly depend on the composition of the base magnesium alloys, the pre-treatment surface cleaning, the type and composition of the solution, and the corresponding operating parameters such as solution temperature and type and degree of agitation. For the stannate bath, González-Nuńez et al. $[10,11]$ demonstrated that the conversion coating mainly consists of crystalline magnesium tin oxide nucleated on a corrosion film intimately contacted with the magnesium substrate. The magnesium tin oxide crystals develop by a nucleation and growth process, which is strongly affected by the composition and microstructure of the base magnesium alloys. In the present study, the nucleation and growth process of the stannate conversion coating was further investigated by systematically varying the composition and temperature of the stannate bath. Furthermore, the detailed microstructure of the conversion coating was examined by cross-sectional transmission electron microscopy (TEM).

\section{Experimental}

\subsection{Conversion coating treatment}

The conversion coatings were made on commercial grade AZ61 magnesium plates. Table 1 shows the composition of the alloy measured by inductively coupled

Table 1

Chemical composition of the AZ61 magnesium alloy

\begin{tabular}{llllllll}
\hline Element & $\mathrm{Mg}$ & $\mathrm{Al}$ & $\mathrm{Zn}$ & $\mathrm{Mn}$ & $\mathrm{Ni}$ & $\mathrm{Fe}$ & $\mathrm{Cu}$ \\
\hline Content (wt.\%) & Bal. & 5.87 & 0.75 & 0.39 & 0.009 & 0.003 & 0.002 \\
\hline
\end{tabular}


Table 2

Composition and temperature of the stannate bath

\begin{tabular}{lll}
\hline Solution composition & & Solution temperature $\left({ }^{\circ} \mathrm{C}\right)$ \\
\hline Chemical & Concentration $\left(\mathrm{g} \mathrm{l}^{-1}\right)$ & \\
\hline $\mathrm{NaOH}$ & $2.5,5,10,15$ & $60,70,80,90$ \\
$\mathrm{~K}_{2} \mathrm{SnO}_{3} \cdot 3 \mathrm{H}_{2} \mathrm{O}$ & $30,40,50,60$ & \\
$\mathrm{NaC}_{2} \mathrm{H}_{3} \mathrm{O}_{2} \cdot 3 \mathrm{H}_{2} \mathrm{O}$ & 10 & \\
$\mathrm{Na}_{4} \mathrm{P}_{2} \mathrm{O}_{7}$ & 50 & \\
\hline
\end{tabular}

plasma-atomic emission spectrometry (ICP-AES). The plate with a size of $25 \times 20 \times 2 \mathrm{~mm}$ was polished from 400 grit down to 2400 grit using emery paper, followed by fine polishing using diamond pastes of 3 and $1 \mu \mathrm{m}$, and finally rinsed with deionised water and cleaned in acetone ultrasonically. After being dried in a stream of hot air, the weight of the coupon was measured by an electronic balance with an accuracy of $0.1 \mathrm{mg}$, and then reserved in a desiccator for treatment of the conversion coating. Prior to the immersion in the stannate bath, the plate was pickled in 11.25 wt. $\%$ hydrofluoric acid solution at room temperature. The acid pickling process and the basic composition of the stannate bath followed those reported by González-Nuńez et al. [10,11]. Table 2 shows the composition and operating conditions of the stannate bath. The stannate solution was not agitated throughout the coating process. After immersion, the plates were thoroughly washed using running deionised water, dried overnight and then re-weighted, allowing the measurement of the weight difference of the plate before and after immersion.

\subsection{Characterization and corrosion test}

The weight difference for the specimens before and after acid pickling was negligible because it was below the detectable limit of the balance. Consequently, the weight difference of the specimen before and after conversion coating treatment could be regarded as the weight change during the course of the treatment. The weight gain was then defined as the weight difference divided by the exposed area subjected to the conversion coating treatment. The surface morphology of the conversion coating was observed via a scanning electron microscope (SEM). The detailed microstructure and composition of the conversion coating was characterized using cross-section TEM specimens, which were prepared by a combined mechanical grinding and ion milling method. The crystal structure of the coating was identified using selected-area electron diffraction technique, meanwhile the composition of the coating was characterized using the energy-dispersive spectrometer (EDS) equipped in TEM using an electron probe of $10 \mathrm{~nm}$ in diameter. The corrosion resistance of AZ61 magnesium plate with a complete coverage of the conversion coating was evaluated according to the CNS-8886 standard for the salt spray test. The salt solution contained $5 \mathrm{wt} . \% \mathrm{NaCl}$. The grade of the corrosion resistance of the specimen was evaluated based on the fraction of the corroded area, and was denoted by a rating number ( $\mathrm{RN}$ ) ranging from 0 to 10 . Smaller $\mathrm{RN}$ corresponds to more severe corrosion. During the course of the salt spray test, each specimen was evaluated every $6 \mathrm{~h}$. 


\section{Results}

\subsection{Effect of bath $p H$}

Various amounts of $\mathrm{NaOH}$ were added in the bath composed of $50 \mathrm{~g} \mathrm{l}^{-1}$ $\mathrm{K}_{2} \mathrm{SnO}_{3} \cdot 3 \mathrm{H}_{2} \mathrm{O}, 10 \mathrm{~g} \mathrm{l}^{-1} \mathrm{NaC}_{2} \mathrm{H}_{3} \mathrm{O}_{2} \cdot 3 \mathrm{H}_{2} \mathrm{O}$, and $50 \mathrm{~g} \mathrm{l}^{-1} \mathrm{Na}_{4} \mathrm{P}_{2} \mathrm{O}_{7}$ at $82^{\circ} \mathrm{C}$ to investigate the effects of bath $\mathrm{pH}$ on the microstructure and corrosion resistance of stannate conversion coatings on AZ61 magnesium alloys. Fig. 1 shows the dependence of the weight gain on the immersion time for the specimens treated in the baths with addition of $2.5,5,10$ and $15 \mathrm{~g}^{-1} \mathrm{NaOH}$, which corresponded to a $\mathrm{pH}$ of 12.59 , $12.97,13.13$ and 13.23 , respectively. The weight gain barely changed with the immersion time during the early stages of treatment, indicating there was an incubation time before the conversion coating began to nucleate and grow. When treating a ZC 71 magnesium alloy and a magnesium-based metal matrix composite in the stannate bath, an incubation time was also observed during the early stages of immersion [10], suggesting that an incubation period exits regardless of the microstructure and composition of the magnesium alloys. After the incubation period, the weigh gain of the specimen increased dramatically, and finally reached a peak value. Then, the weight gain of the specimens treated in the baths containing 2.5 and $5 \mathrm{~g}^{-1} \mathrm{NaOH}$ remained unchanged as the immersion proceeded. In contrast, prolonged immersion eventually caused a decrease in the weight gain for the specimens treated in the bath containing 10 and $15 \mathrm{~g} \mathrm{l}^{-1} \mathrm{NaOH}$. The incubation time and maximum weight gain apparently increased with increasing bath $\mathrm{pH}$. The treatment time when the weight gain reached its peak value also increased with increasing bath $\mathrm{pH}$, as shown in Fig. 2.

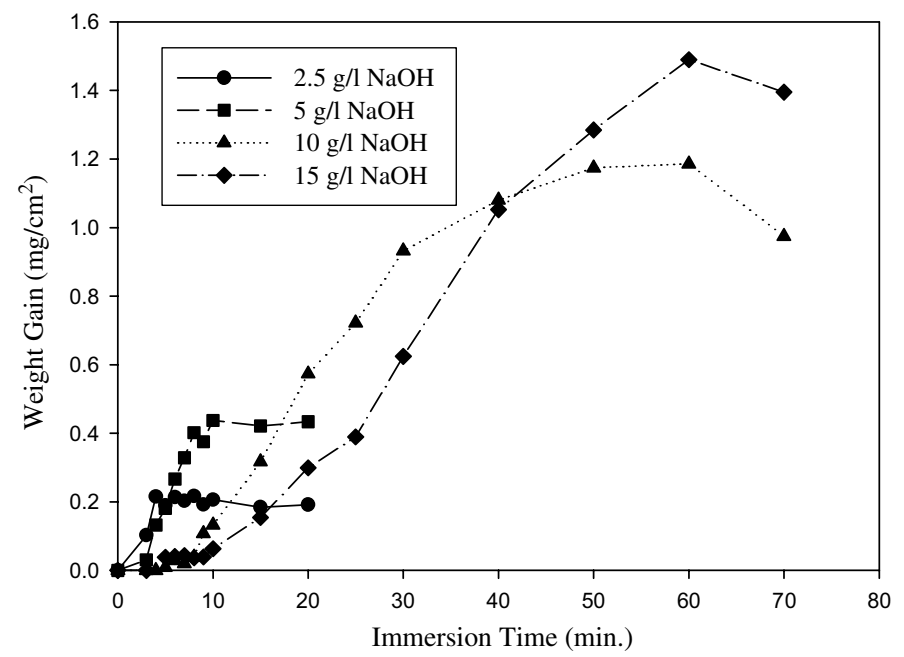

Fig. 1. Dependence of weight gain on the immersion time for the specimens treated in the baths containing $50 \mathrm{~g} \mathrm{l}^{-1} \mathrm{~K}_{2} \mathrm{SnO}_{3} \cdot 3 \mathrm{H}_{2} \mathrm{O}, 10 \mathrm{~g} \mathrm{l}^{-1} \mathrm{NaC}_{2} \mathrm{H}_{3} \mathrm{O}_{2} \cdot 3 \mathrm{H}_{2} \mathrm{O}, 50 \mathrm{~g} \mathrm{l}^{-1} \mathrm{Na}_{4} \mathrm{P}_{2} \mathrm{O}_{7}$ and various amounts of $\mathrm{NaOH}$ at $82{ }^{\circ} \mathrm{C}$. 


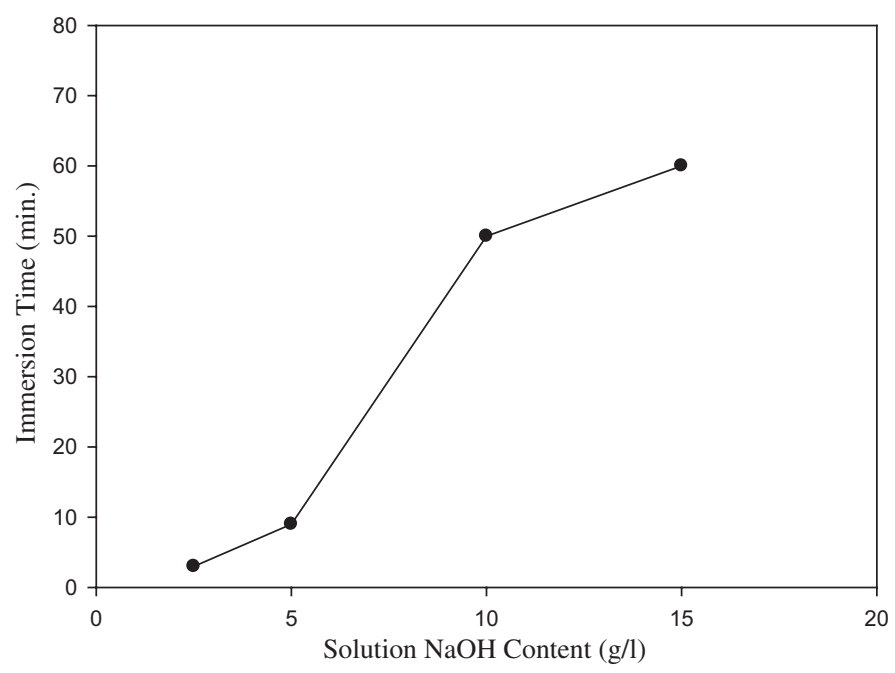

Fig. 2. Effect of bath $\mathrm{NaOH}$ content on the immersion time when the weight gain reached a maximum value. The basic composition of the $82{ }^{\circ} \mathrm{C}$ bath contains $50 \mathrm{~g} \mathrm{l}^{-1} \mathrm{~K}_{2} \mathrm{SnO}_{3} \cdot 3 \mathrm{H}_{2} \mathrm{O}, 10 \mathrm{~g} \mathrm{l}^{-1} \mathrm{NaC}_{2} \mathrm{H}_{3} \mathrm{O}_{2}$. $3 \mathrm{H}_{2} \mathrm{O}$ and $50 \mathrm{~g} \mathrm{l}^{-1} \mathrm{Na}_{4} \mathrm{P}_{2} \mathrm{O}_{7}$.

Figs. 3 and 4 show a series of SEM micrographs illustrating the evolution of the conversion coating in the bath containing 5 and $15 \mathrm{~g}^{-1} \mathrm{NaOH}$, respectively. For the bath containing $5 \mathrm{~g}^{-1} \mathrm{NaOH}$, the incubation time was approximately $3 \mathrm{~min}$, when numerous nuclei formed, although many areas remained free of nuclei (Fig. 3(a)). As the immersion time was increased to $4 \mathrm{~min}$, the pre-existing nuclei grew to an average size of around $2 \mu \mathrm{m}$, which was limited by the impingement of the nuclei with each other. The area that was free of nuclei after 3 min of immersion was now dotted with relatively small nuclei, which would again grow to a final size when they coalesced with the surrounding nuclei. This rapid growth of the nuclei caused an abrupt increase in the weight gain. Furthermore, once the nuclei coalesced with each other, their growth presumably stopped, and the coating reaction occurred on the areas that either remained free of nuclei or were dotted with dispersive tiny nuclei. Finally, the surface of the magnesium plate was fully covered with spherical particles. The weight gain then barely changed with continued immersion. Up to this stage, some sites of discontinuity remained. Such sites, which exhibited as either bare spots or crevices, provided the pathways for ion and electrolyte transportation. Coating reaction continued via the diffusion of the reacting species through these sites and caused the formation of scattered particles on top of the particle coating layer, as indicated by the arrow in Fig. 3(e) and (f). Since the formation of new particles on the existing coating layer was markedly limited by the bare spots and crevices available for ion and electrolyte transportation, the maximum weight gain and the thickness of the specimen were predominantly determined by the size of the particles formed right on top of the magnesium plate. Furthermore, increasing bath $\mathrm{NaOH}$ concentration notably prohibited the nucleation of the coating; that is, at the end of the incubation 

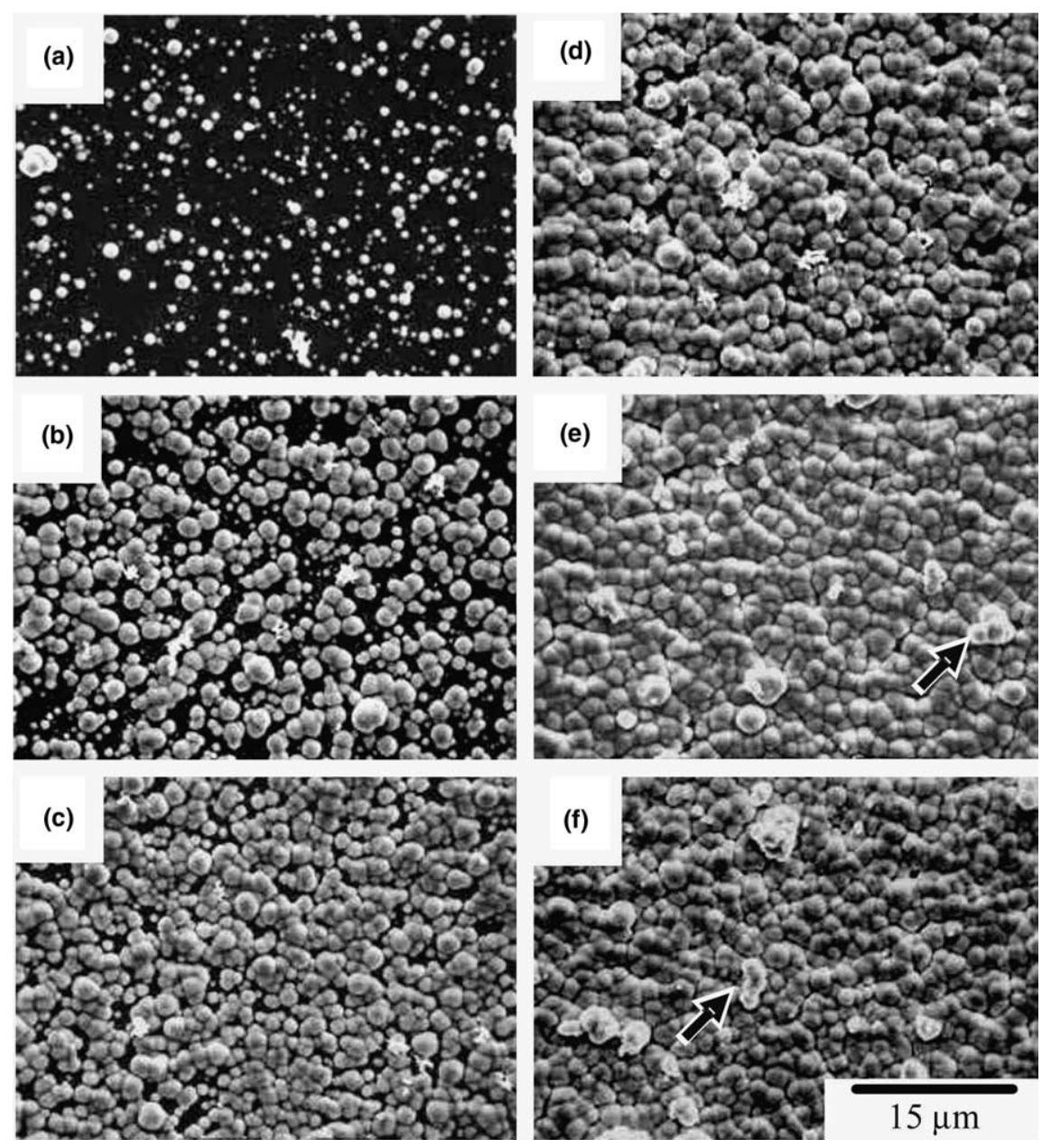

Fig. 3. A series of SEM micrographs showing the surface morphology of the specimen treated in the bath composed of $5 \mathrm{~g} \mathrm{l}^{-1} \mathrm{NaOH}, 50 \mathrm{~g} \mathrm{l}^{-1} \mathrm{~K}_{2} \mathrm{SnO}_{3} \cdot 3 \mathrm{H}_{2} \mathrm{O}, 10 \mathrm{~g} \mathrm{l}^{-1} \mathrm{NaC}_{2} \mathrm{H}_{3} \mathrm{O}_{2} \cdot 3 \mathrm{H}_{2} \mathrm{O}$ and $50 \mathrm{~g} \mathrm{l}^{-1} \mathrm{Na}_{4} \mathrm{P}_{2} \mathrm{O}_{7}$ for (a) 3, (b) 4, (c) 5, (d) 6, (e) 8 and (f) $10 \mathrm{~min}$ at $82{ }^{\circ} \mathrm{C}$.

period, the population density of the nuclei formed in the bath containing $5 \mathrm{~g}^{-1}$ $\mathrm{NaOH}$ was substantially larger than that in the bath containing $15 \mathrm{~g}^{-1} \mathrm{NaOH}$ (Figs. 3(b) and 4(b)). Consequently, compared to those formed in the bath containing $5 \mathrm{~g}^{-1} \mathrm{NaOH}$, the nuclei formed in the bath containing $15 \mathrm{~g}^{-1} \mathrm{NaOH}$ grew to a larger size and its resulting maximum weight gain was larger. Fig. 5 shows the surface morphology of the conversion coatings formed in the baths of distinct $\mathrm{pHs}$ when the weight gain of the specimen reached a maximum value. Apparently, the average particle size increased with increasing bath $\mathrm{pH}$. The conversion coating formed in the bath containing $2.5 \mathrm{~g}^{-1} \mathrm{NaOH}$ had notably high integrity, and contained least and smallest sites of discontinuity among the specimens treated in the 

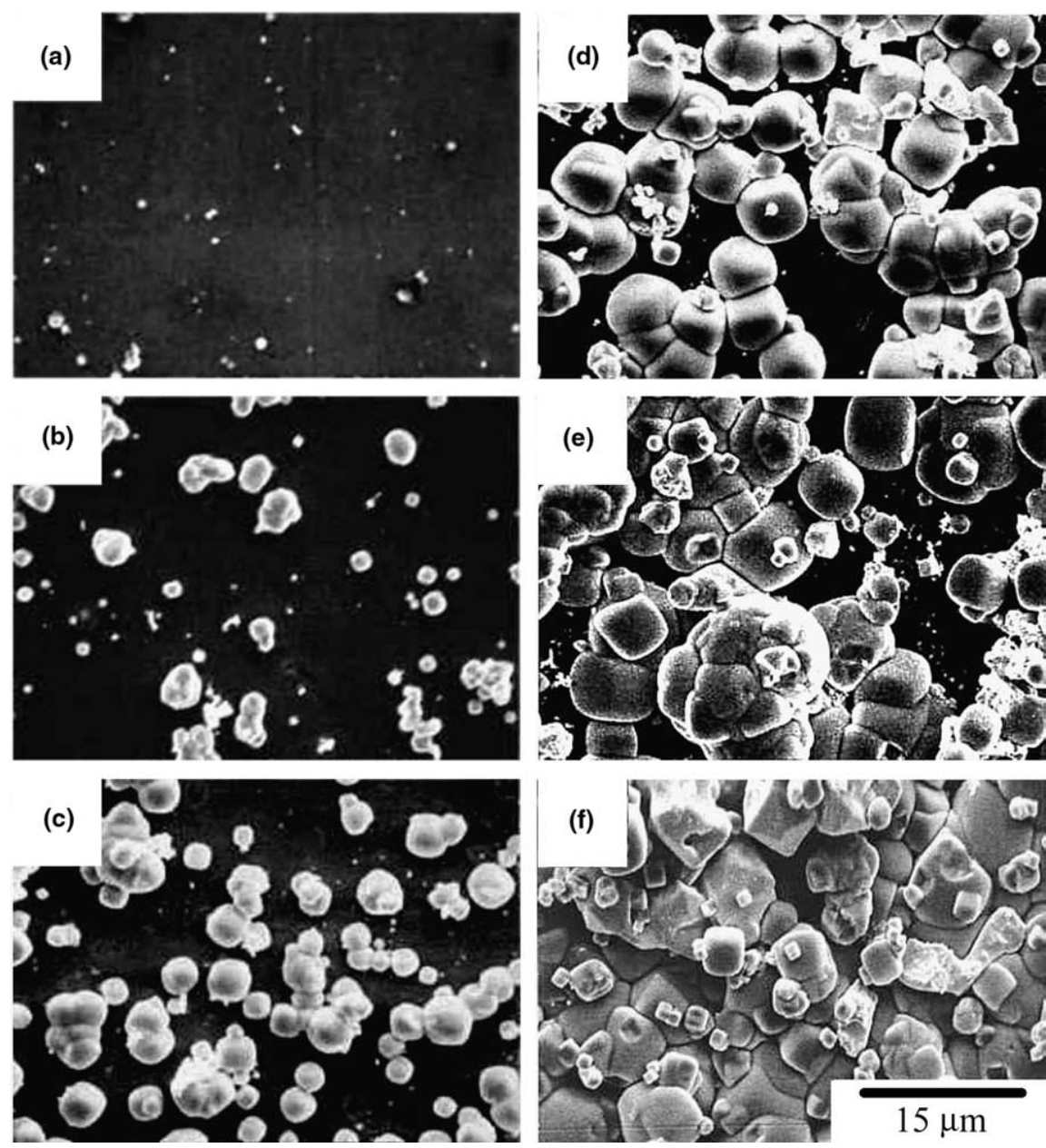

Fig. 4. A series of SEM micrographs showing the surface morphology of the specimen treated in the bath containing $15 \mathrm{~g} \mathrm{l}^{-1} \mathrm{NaOH}, 50 \mathrm{~g} \mathrm{l}^{-1} \mathrm{~K}_{2} \mathrm{SnO}_{3} \cdot 3 \mathrm{H}_{2} \mathrm{O}, 10 \mathrm{~g} \mathrm{l}^{-1} \mathrm{NaC}_{2} \mathrm{H}_{3} \mathrm{O}_{2} \cdot 3 \mathrm{H}_{2} \mathrm{O}$ and $50 \mathrm{~g}^{-1} \mathrm{Na}_{4} \mathrm{P}_{2} \mathrm{O}_{7}$ for (a) 5 , (b) 10 , (c) 20 , (d) 30 , (e) 40 and (f) 60 min at $82^{\circ} \mathrm{C}$.

baths of distinct pHs. After salt spray test, the coating composed of the finest particles (Fig. 6) exhibited the best corrosion resistance among the four specimens shown in Fig. 5. The fact that the specimens treated in the bath containing 10 and $15 \mathrm{~g}^{-1}$ $\mathrm{NaOH}$ corroded more severe than the AZ61 plate without conversion coating was probably due to the relatively-large crevices, which were once filled with the salt solution, facilitated the crevice corrosion [21], whereas the AZ61 magnesium alloy contained $\beta$ phase, which have been shown to improve the corrosion resistance of the alloy [22].

Fig. 7 shows the cross-sectional TEM characterization of the specimen treated in the bath containing $50 \mathrm{~g}^{-1} \mathrm{~K}_{2} \mathrm{SnO}_{3} \cdot 3 \mathrm{H}_{2} \mathrm{O}, 10 \mathrm{~g} \mathrm{l}^{-1} \mathrm{NaC}_{2} \mathrm{H}_{3} \mathrm{O}_{2} \cdot 3 \mathrm{H}_{2} \mathrm{O}, 50 \mathrm{~g} \mathrm{l}^{-1}$ 

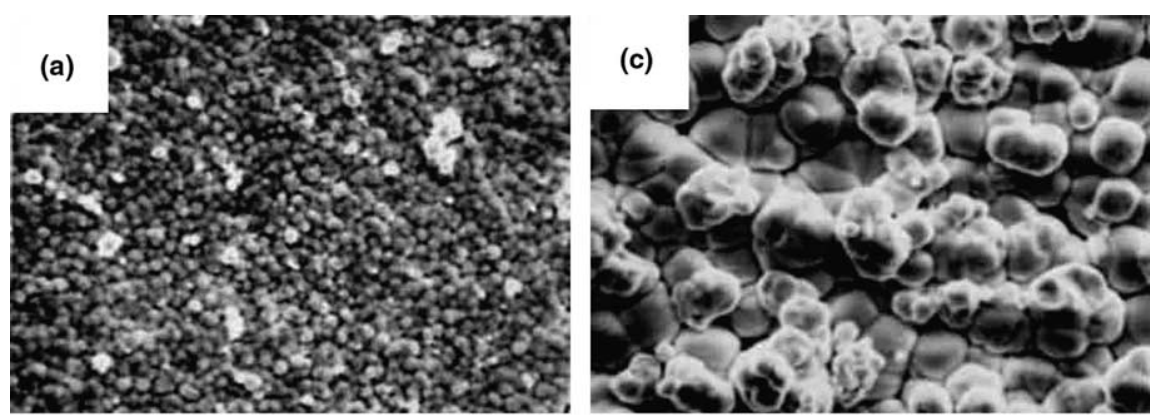

(b)
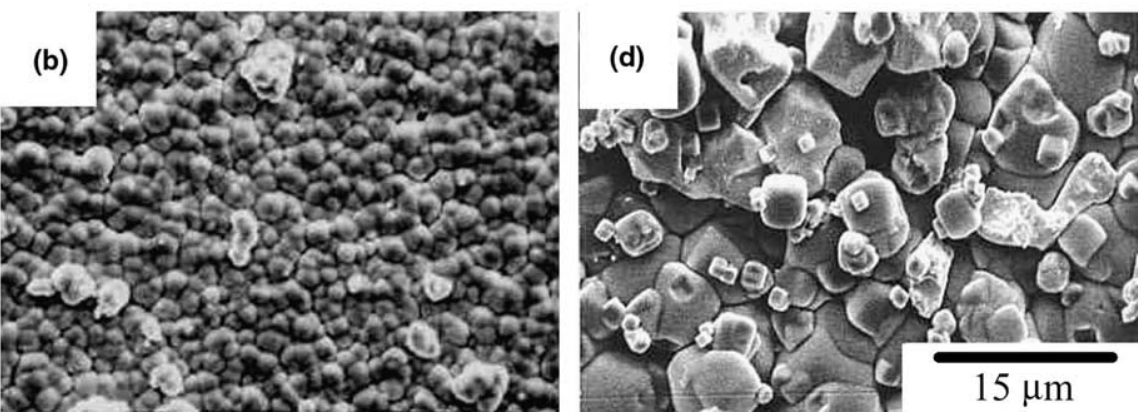

Fig. 5. Surface morphology of the specimen with a maximum weight gain of the conversion coating formed in the baths with the addition of (a) $2.5 \mathrm{~g} \mathrm{l}^{-1} \mathrm{NaOH}$ for $5 \mathrm{~min}$, (b) $5 \mathrm{~g}^{-1} \mathrm{NaOH}$ for $10 \mathrm{~min}$, (c) $10 \mathrm{~g} \mathrm{l}^{-1} \mathrm{NaOH}$ for $50 \mathrm{~min}$, and (d) $15 \mathrm{~g} \mathrm{l}^{-1} \mathrm{NaOH}$ for $60 \mathrm{~min}$. The basic composition of the $82{ }^{\circ} \mathrm{C}$ bath contains $50 \mathrm{~g}^{-1} \mathrm{~K}_{2} \mathrm{SnO}_{3} \cdot 3 \mathrm{H}_{2} \mathrm{O}, 10 \mathrm{~g} \mathrm{l}^{-1} \mathrm{NaC}_{2} \mathrm{H}_{3} \mathrm{O}_{2} \cdot 3 \mathrm{H}_{2} \mathrm{O}$ and $50 \mathrm{~g} \mathrm{l}^{-1} \mathrm{Na}_{4} \mathrm{P}_{2} \mathrm{O}_{7}$.

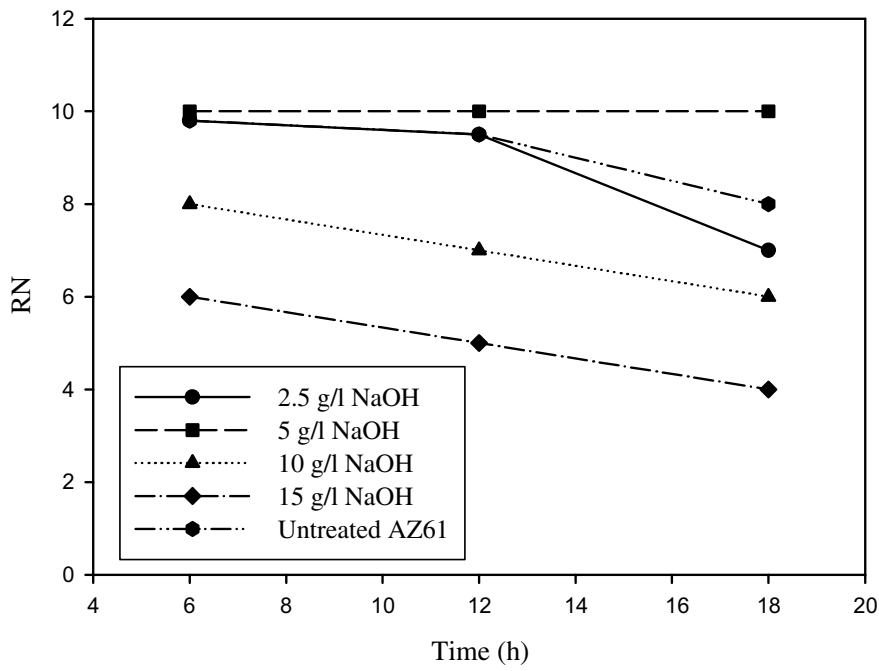

Fig. 6. Rating number of the specimen shown in Fig. 5 as a function of the exposure time during salt spray test. 
(a)
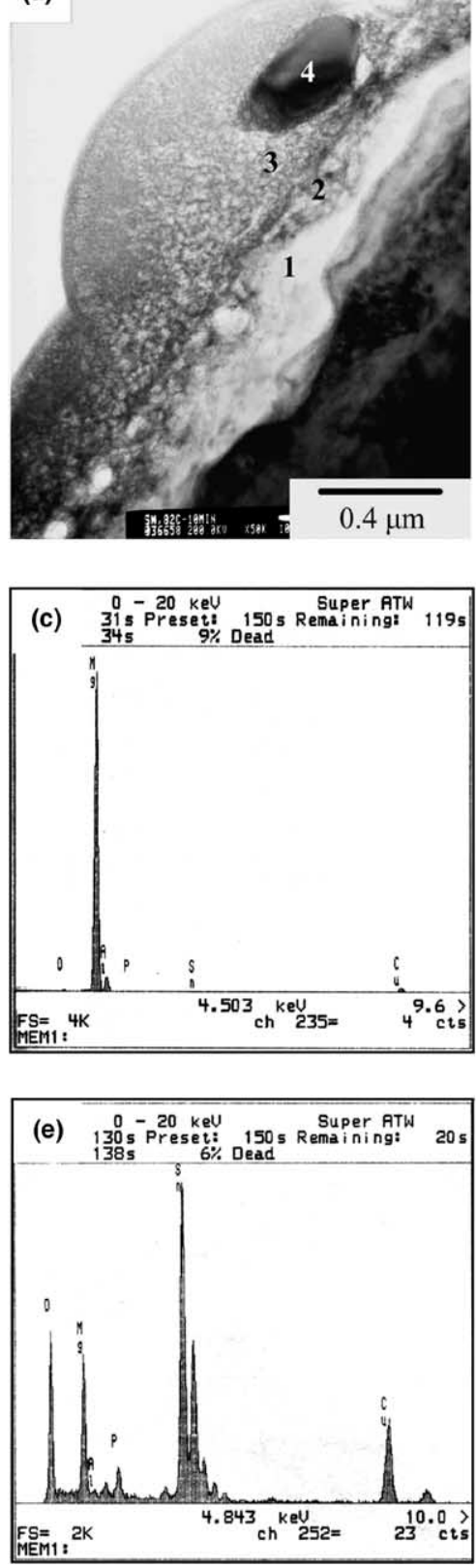

(b)
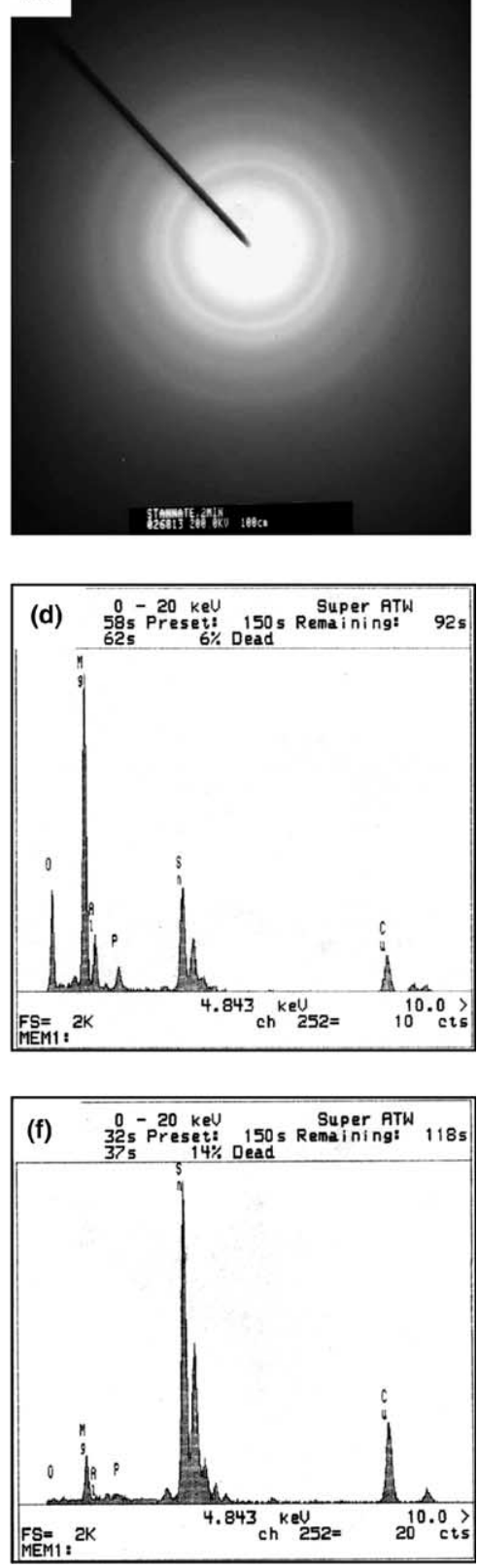

Fig. 7. Cross-sectional TEM characterization of the specimen treated in the bath containing $5 \mathrm{~g}^{-1}$ $\mathrm{NaOH}, 50 \mathrm{~g}^{-1} \mathrm{~K}_{2} \mathrm{SnO}_{3} \cdot 3 \mathrm{H}_{2} \mathrm{O}, 10 \mathrm{~g} \mathrm{l}^{-1} \mathrm{NaC}_{2} \mathrm{H}_{3} \mathrm{O}_{2} \cdot 3 \mathrm{H}_{2} \mathrm{O}$ and $50 \mathrm{~g}^{-1} \mathrm{Na}_{4} \mathrm{P}_{2} \mathrm{O}_{7}$ for 10 min at $82{ }^{\circ} \mathrm{C}$ : (a) bright field, (b) SADP from a hemispherical particle, and (c)-(f) the EDS spectra taken from the areas marked as $1-4$ in (a), respectively. 
Table 3

Results of the EDS spectra shown in Fig. 7(c)-(f)

\begin{tabular}{llllll}
\hline Area marked as & \multicolumn{5}{l}{ Element (wt.\%) } \\
\cline { 2 - 6 } & $\mathrm{Mg}$ & $\mathrm{Al}$ & $\mathrm{O}$ & $\mathrm{P}$ & $\mathrm{Sn}$ \\
\hline 1 & 95.5 & 4.5 & - & - & - \\
2 & 28.2 & 7.1 & 12.8 & 11.6 & 40.3 \\
3 & 10.1 & - & 13.7 & 2.8 & 73.4 \\
4 & 2.7 & - & 1.9 & 1.3 & 94.1 \\
\hline
\end{tabular}

$\mathrm{Na}_{4} \mathrm{P}_{2} \mathrm{O}_{7}$ and $5 \mathrm{~g} 1^{-1} \mathrm{NaOH}$ at $82{ }^{\circ} \mathrm{C}$ for $10 \mathrm{~min}$. The conversion coating consisted of hemispherical particles, which were porous and contained nanograins dispersed within the amorphous matrix, as illustrated by the selected-area electron diffraction pattern (Fig. 7(b)). Right beneath the hemispherical particle layer, a rather porous layer (marked by 2 in Fig. 7(a)) intimately contacted with the magnesium substrate (marked by 1 in Fig. 7(a)). The EDS spectra taken from the areas marked by $1-4$ in Fig. 7(a) are shown in Fig. 7(d)-(f), respectively, and the results are quantified in Table 3. The magnesium substrate contained $4.5 \mathrm{wt} . \%$ of aluminum and the ratio (in weight) of aluminum to magnesium was approximately 0.05 . The layer of the conversion coating adjacent to the magnesium substrate had the ratio of aluminum to magnesium being around 0.25 , which was significantly higher than that of the magnesium substrate. On the contrary, the aluminum in the hemispherical particle was below the detectable limit of EDS. This larger aluminum to magnesium weight ratio associated with the layer intimately contacted with the magnesium substrate suggests the aluminum ions dissolved from the magnesium substrate was preferentially re-deposited into the conversion coating layer. The hemispherical particle was mainly composed of tin, magnesium, oxygen species and trace of phosphorus, which is in agreement with the magnesium tin oxide identified by González-Nuńez et al. [10,11]. Finally, the particle (marked as 4 in Fig. 7(a)) embedded in the hemispherical particle layer consisted of tin, magnesium, oxygen and phosphorus species. Furthermore, this particle contained high tin content ( $94.1 \mathrm{wt} . \%)$, but low oxygen (1.9 wt.\%). Therefore, it may consist of magnesium tin oxide, tin hydroxide and metallic tin. This suggests that stannate ions were potentially reduced in accompanying with the oxidation of magnesium plate in the stannate solution.

\subsection{Effect of bath temperature}

Fig. 8 shows the effect of bath temperature on the weight gain of the specimen treated in the bath composed of $10 \mathrm{~g}^{-1} \mathrm{NaOH}, 50 \mathrm{~g}^{-1} \mathrm{~K}_{2} \mathrm{SnO}_{3} \cdot 3 \mathrm{H}_{2} \mathrm{O}, 10 \mathrm{~g}^{-1}$ $\mathrm{NaC}_{2} \mathrm{H}_{3} \mathrm{O}_{2} \cdot 3 \mathrm{H}_{2} \mathrm{O}$ and $50 \mathrm{~g}^{-1} \mathrm{Na}_{4} \mathrm{P}_{2} \mathrm{O}_{7}$ for 9 min. When the bath temperature was increased from 60 to $80^{\circ} \mathrm{C}$, the weight gain slightly increased, followed by a rapid increase as the temperature was further increased to $90{ }^{\circ} \mathrm{C}$. The dependence of the weight gain on the immersion time is shown in Fig. 9 for the specimens treated in the same bath at distinct temperatures. Like the effect of bath $\mathrm{pH}$, an incubation period was observed regardless of the bath temperature. The incubation time gener- 


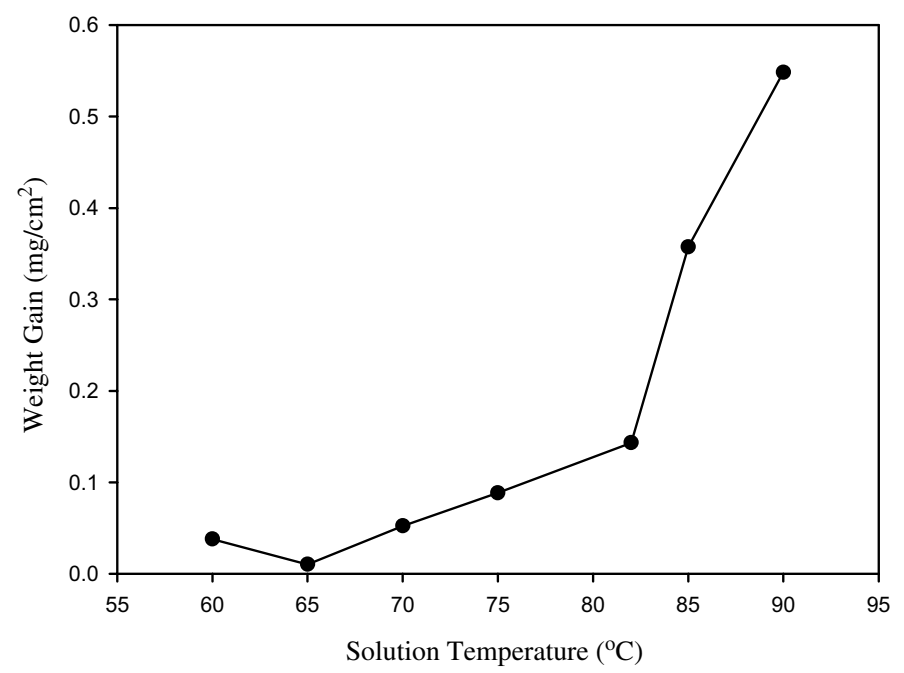

Fig. 8. Effect of bath temperature on the weight gain of the specimen treated in the bath containing $10 \mathrm{~g}^{-1} \mathrm{NaOH}, 50 \mathrm{~g} \mathrm{l}^{-1} \mathrm{~K}_{2} \mathrm{SnO}_{3} \cdot 3 \mathrm{H}_{2} \mathrm{O}, 10 \mathrm{~g} \mathrm{l}^{-1} \mathrm{NaC}_{2} \mathrm{H}_{3} \mathrm{O}_{2} \cdot 3 \mathrm{H}_{2} \mathrm{O}$ and $50 \mathrm{~g} \mathrm{l}^{-1} \mathrm{Na}_{4} \mathrm{P}_{2} \mathrm{O}_{7}$.

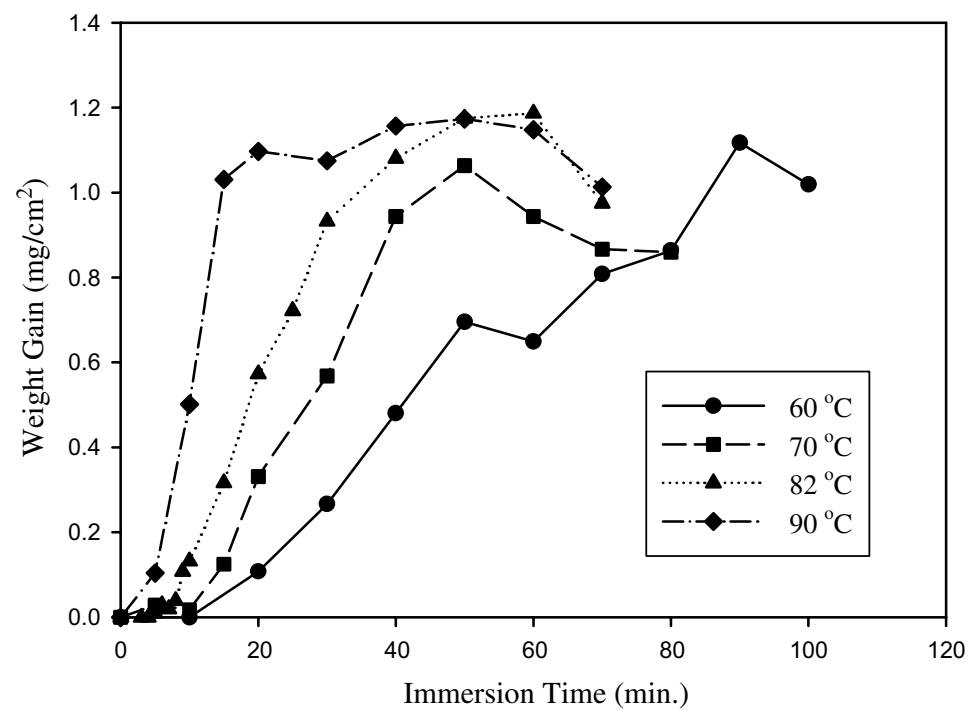

Fig. 9. Weight gain of the specimen treated in the baths at different temperatures as a function of immersion time. The coating was made from the same bath shown in Fig. 8.

ally decreased with increasing bath temperature, whereas the maximum weight gain was nearly independent on the bath temperature. Furthermore, increasing bath temperature led to a higher rate in the increase of the weight gain. For example, the immersion time when the weight gain reached its peak value was approximately 
90, 50, 50 and $20 \mathrm{~min}$ for the specimens treated in the baths at $60,70,80$ and $90{ }^{\circ} \mathrm{C}$, respectively. Similarly, the weight gain exhibited little change once the magnesium plate was fully covered with hemispherical particles. This saturation in weight gain suggests that the nucleation and growth of new particles was significantly retarded once the specimen was covered with a complete coating, which prevented the further attack of the magnesium substrate by the solution.

Fig. 10 shows that the average size of the particles was approximately $5 \mu \mathrm{m}$ regardless of the bath temperature, indicating the population density of the nuclei was apparent not a function of the bath temperature although the nucleation and growth rate of the particle increased with increasing bath temperature. This observation is in good consistence with the result that the bath temperature had little effect on the maximum weight gain of the specimen.

\subsection{Effect of bath stannate ion content}

Like the solution $\mathrm{pH}$, the bath stannate ion content significantly affected the incubation time, maximum weight gain and the population density of the particles, as shown in Figs. 11 and 12. Both the incubation time and maximum weight gain decreased with increasing stannate ion content, whereas the population density increased with the stannate ion content. The weight gain of the specimen immersed
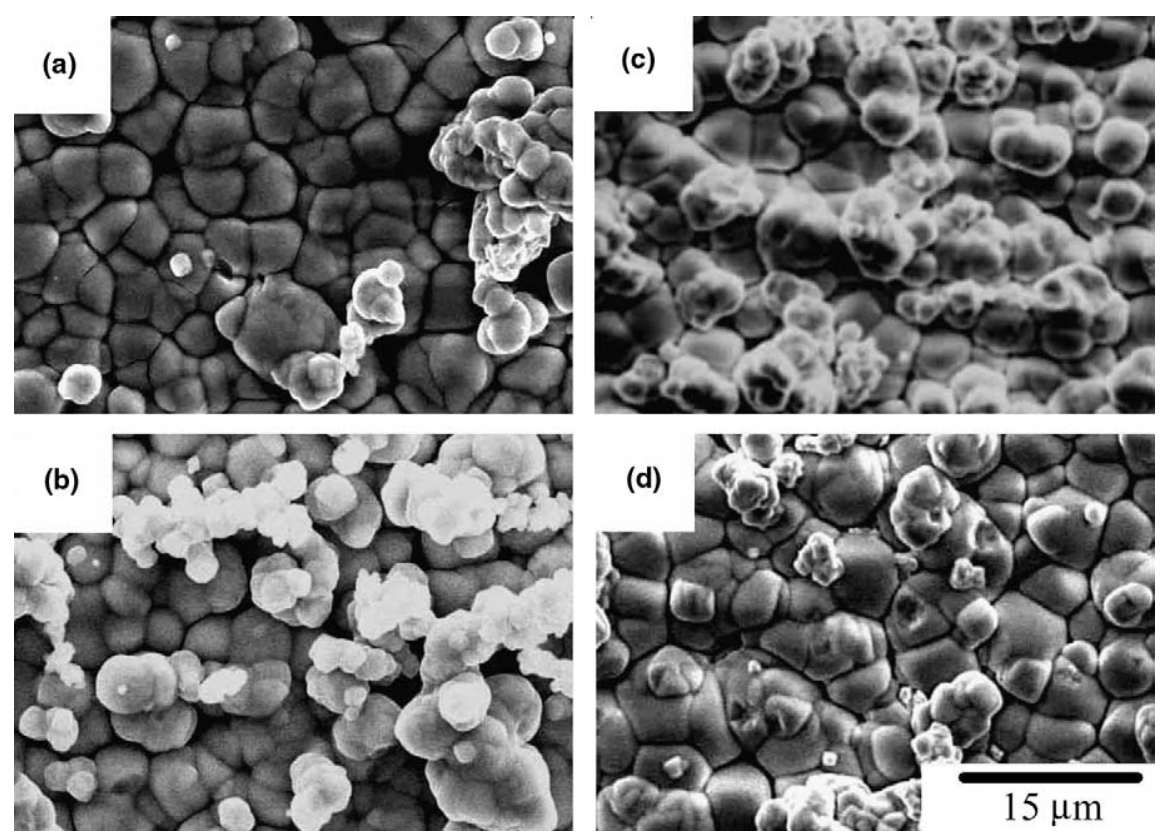

Fig. 10. Surface morphology of the conversion coatings formed in the bath containing $10 \mathrm{~g}^{-1} \mathrm{NaOH}_{\text {, }}$ $50 \mathrm{~g} \mathrm{l}^{-1} \mathrm{~K}_{2} \mathrm{SnO}_{3} \cdot 3 \mathrm{H}_{2} \mathrm{O}, 10 \mathrm{~g}^{-1} \mathrm{NaC}_{2} \mathrm{H}_{3} \mathrm{O}_{2} \cdot 3 \mathrm{H}_{2} \mathrm{O}$ and $50 \mathrm{~g}^{-1} \mathrm{Na}_{4} \mathrm{P}_{2} \mathrm{O}_{7}$ at (a) 60, (b) 70 , (c) 80 and (d) $90{ }^{\circ} \mathrm{C}$. 


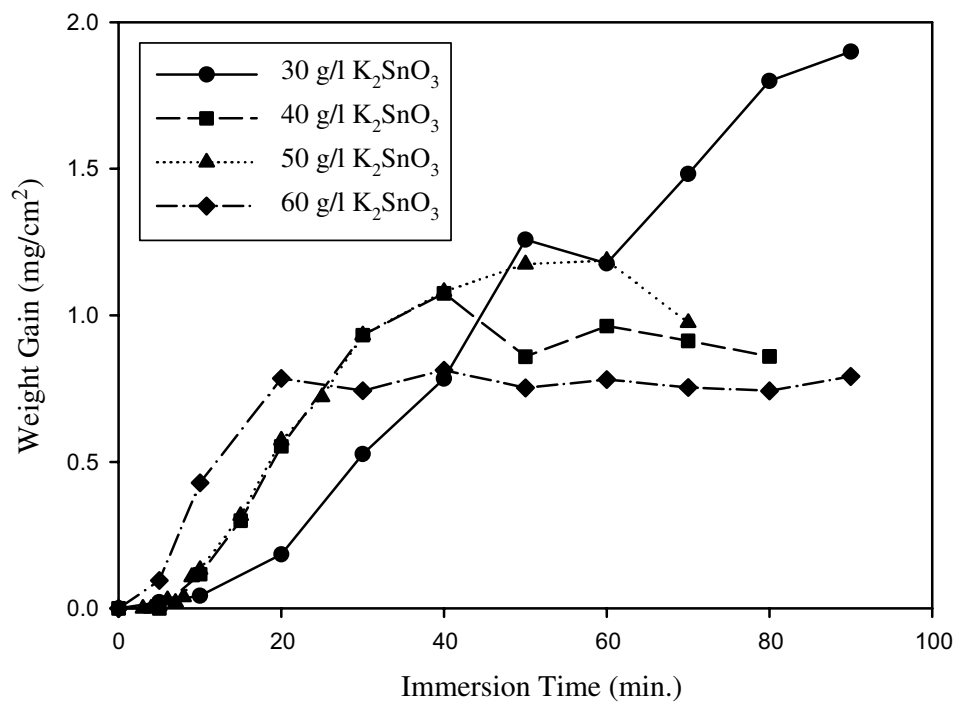

Fig. 11. Weight gain of the specimen as a function of the bath stannate ion content. The basic composition of the $82^{\circ} \mathrm{C}$ bath contains $10 \mathrm{~g} \mathrm{l}^{-1} \mathrm{NaOH}, 10 \mathrm{~g} \mathrm{l}^{-1} \mathrm{NaC}_{2} \mathrm{H}_{3} \mathrm{O}_{2} \cdot 3 \mathrm{H}_{2} \mathrm{O}$ and $50 \mathrm{~g} \mathrm{l}^{-1} \mathrm{Na}_{4} \mathrm{P}_{2} \mathrm{O}_{7}$.
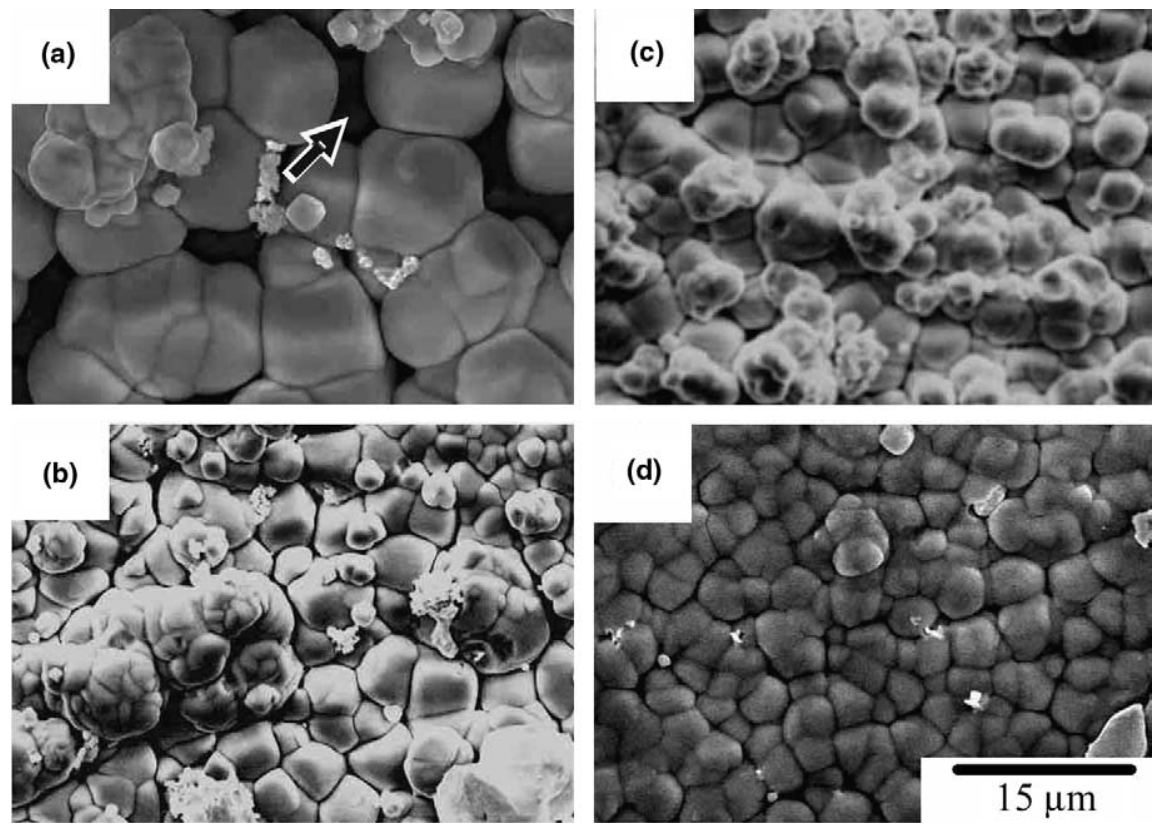

Fig. 12. Surface morphology of the conversion coatings formed in the bath containing $10 \mathrm{~g}^{-1} \mathrm{NaOH}_{\text {, }}$ $10 \mathrm{~g} \mathrm{l}^{-1} \mathrm{NaC}_{2} \mathrm{H}_{3} \mathrm{O}_{2} \cdot 3 \mathrm{H}_{2} \mathrm{O}, 50 \mathrm{~g} \mathrm{l}^{-1} \mathrm{Na}_{4} \mathrm{P}_{2} \mathrm{O}_{7}$, and (a) 30, (b) 40, (c) 50 and (d) $60 \mathrm{~g} \mathrm{l}^{-1} \mathrm{~K}_{2} \mathrm{SnO}_{3} \cdot 3 \mathrm{H}_{2} \mathrm{O}$ at $82{ }^{\circ} \mathrm{C}$. 
in the bath containing $60 \mathrm{~g}^{-1} \mathrm{~K}_{2} \mathrm{SnO}_{3} \cdot 3 \mathrm{H}_{2} \mathrm{O}$ hardly changed with continued immersion. On the contrary, the weight gain of the plate immersed in the bath with $30 \mathrm{~g} \mathrm{l}^{-1} \mathrm{~K}_{2} \mathrm{SnO}_{3} \cdot 3 \mathrm{H}_{2} \mathrm{O}$ kept increasing up to the maximum immersion time studied, i.e. $90 \mathrm{~min}$. The difference in the weight gain between various coatings correlates well to their surface morphology shown in Fig. 12. For example, the average size of the hemispherical particles decreased with increasing stannate ion content. Moreover, the integrity of the coating appeared to increase with decreasing particle size, leaving fewer sites of discontinuity (Fig. 12(d)). In contrast, relatively-large bare spots (marked by the arrow in Fig. 12(a)) were observed on the specimen immersed in the bath containing $30 \mathrm{~g} \mathrm{l}^{-1} \mathrm{~K}_{2} \mathrm{SnO}_{3} \cdot 3 \mathrm{H}_{2} \mathrm{O}$ for $90 \mathrm{~min}$. These bare spots accounted for the continuous increase in the weight gain with continued immersion when the specimen was treated in the bath containing $30 \mathrm{~g} \mathrm{l}^{-1} \mathrm{~K}_{2} \mathrm{SnO}_{3} \cdot 3 \mathrm{H}_{2} \mathrm{O}$.

\section{Discussion}

Conversion coatings on magnesium alloys treated in the stannate solution have been shown to develop by a nucleation and growth process [10,11]. In the present study, an incubation time was also observed prior to obvious growth of the existing nuclei on the AZ61 plate treated in the stannate bath. Such an incubation time is needed for the surface of the substrate to be corroded; thereby releasing $\mathrm{Mg}^{2+}$ ions to the electrode/solution interface. The nucleation rate of the hemispherical nuclei is related to the incubation time, whereas the population density of the nuclei depends on the solution $\mathrm{pH}$ and potassium stannate concentration. Solution temperature affects the nucleation rate, but shows little effect on the population density of the nuclei.

The effects of the solution $\mathrm{pH}$ and potassium stannate concentration can be ascribed to the creation of a suitable condition for the nuclei to precipitate. For example, once the AZ61 plate is immersed in the stannate solution, the $\mathrm{Mg}-\mathrm{Al}$ solid solution is oxidized to form $\mathrm{Mg}^{2+}$ and $\mathrm{Al}^{3+}$ ions, and water can be decomposed with the evolution of hydrogen. In a sufficient alkaline solution, $\mathrm{Mg}^{2+}$ ions will be redeposited as magnesium hydroxide onto the magnesium substrate and $\mathrm{Al}^{3+}$ ions will dissolve in the solution as aluminate ions [23]. The formation of magnesium hydroxide causes the passivation of AZ61 alloy. Dissolution of magnesium and decomposition of water are then limited by the ion transportation through the porous magnesium hydroxide layer. The fact that the EDS spectra taken from the porous magnesium hydroxide layer contains tin signal (Fig. 7(d)) indicates that the stannate ions are indeed incorporated into porous magnesium hydroxide layer. In the stannate solution used for this study, the alkalinity of the solution is sufficient to maintain the dissolution of stannate ions in the solution. However, as demonstrate by González-Nuńez et al. [10,11], the magnesium tin oxide can precipitate once the concentration of $\mathrm{Mg}^{2+}$ and stannate ions reaches a critical value. Therefore, the diffusion of $\mathrm{Mg}^{2+}$ ions to the hydroxide layer/solution interface and the interfacial $\mathrm{pH}$ increase due to hydrogen discharge create an environment for the nucleation of the hemispherical particles. Increasing solution $\mathrm{pH}$ increases the stability of the magnesium 
hydroxide layer; thereby retarding the dissolution and diffusion of $\mathrm{Mg}^{2+}$ ions into the substrate/solution interface. Furthermore, higher $\mathrm{pH}$ favors dissolution of stannate ions in the solution and prohibits the precipitation of magnesium tin oxide. Consequently, the incubation time decreases and the population density of the nuclei increases with decreasing bath $\mathrm{NaOH}$ content. Increasing bath stannate ion concentration also facilitates the nucleation of the particles, resulting in shorter incubation time and larger nuclei population density. In general, diffusion of various ions is enhanced with increasing bath temperature, thus leading to a shorter incubation time. The bath temperature, however, shows little effect on the nuclei population density because the interfacial $\mathrm{pH}$ and stannate ion concentration are not directly related to the bath temperature.

Because the conversion coating layer develops via the merge of hemispherical particles, the sites without the coverage of hemispherical particles exists. Such sites of discontinuity have been shown to be related to the microstructure and composition of the magnesium alloys [11]. The results of the present study further demonstrate that finer hemispherical particles lead to fewer and smaller sites of discontinuity. Accordingly, the corrosion resistance of the conversion coating is improved with finer particles, which are preferably formed at less alkaline solution with higher stannate ion contents. Furthermore, the conditions favoring the formation of finer particles also reduces the immersion time required for producing the conversion coating with optimal corrosion resistance.

Although the magnesium tin oxide seems to be the most plausible phase to precipitate $[10,11]$, the observation of tin-rich particles dispersed within the conversion coating suggests that other than hydrogen discharge, reduction of stannate ions to metallic tin is another possible cathodic reaction during the treatment. Following the reduction of stannate ions to form metallic tin in aqueous solution, $\mathrm{HSnO}^{2-}$ ions can form as an intermediate species [23]. This suggests that except magnesium tine oxide, magnesium stannous oxide potentially exists in the conversion coating.

\section{Conclusions}

The following conclusions have been reached in the present study on the effects of bath $\mathrm{pH}$, temperature and stannate ion content on the microstructure and corrosion resistance of stannate conversion coatings on AZ61 magnesium alloys.

(1) The stannate conversion coating on AZ61 alloys consisted of two layers: a relatively porous layer contacting with the substrate and a hemispherical particle layer as the major overlay. Compared to the substrate, the porous layer was enriched with aluminum species.

(2) An incubation time was observed for the nucleation of the hemispherical particle layer. Lowing bath $\mathrm{pH}$ and increasing bath temperature as well as stannate ion concentration resulted in a shorter incubation time.

(3) A complete hemispherical particle layer formed once the individual particles grew and coalesced with each other. The coating then showed little change 
in the morphology and weight gain with continued immersion. Consequently, a larger population density of the nuclei resulted in finer particles, which corresponded to a smaller maximum weight gain and a thinner coating thickness. Lower bath $\mathrm{pH}$ and higher stannate ion concentration notably increased the population density of the nuclei.

(4) The merge of the hemispherical particles inevitably left some sites of discontinuity, which were detrimental to the corrosion resistance of the coating. A less alkaline solution with higher stannate ion content promoted the nucleation of the nuclei and hence favored the formation of finer particles. The major overlay consisted of fine particles contained less and smaller sites of discontinuity, and exhibited better corrosion resistance than the coating composed of coarse particles.

(5) The formation of stannate conversion coatings on AZ61 magnesium alloys involves a nucleation and growth process. The dissolution of the substrate in the early stage of immersion is essential for the nucleation and growth of hemispherical particles. Reactions involved in the formation of the conversion coating include oxidization/dissolution of the substrate, decomposition of water and perhaps reduction of stannate ions.

\section{Acknowledgement}

This research was supported by the National Science Council, Republic of China, under grant No. 902216E212001. The authors thank Dr. W.P. Hong, Chung-Shan Institute of Science and Technology, for providing the materials for this study. Ms. L.C. Wang, National Sun Yat-sen University, is acknowledged for her assistance with the TEM work. This study made use of the Electron Microscopes of National Sun Yat-sen University and National Taiwan University, supported by the National Science Council, Republic of China.

\section{References}

[1] Y. Kojima, Mater. Trans. JIM 42 (2001) 1154.

[2] J.E. Gray, B. Luan, J. Alloys Compd. 336 (2002) 88.

[3] T. Biestek, J. Weber, Electrolytic and Chemical Conversion Coatings, first ed., Portcullis Press Ltd., Poland, 1976, pp. 208-210.

[4] S. Ono, K. Asami, T. Osaka, N. Masuko, J. Electrochem. Soc. 143 (1996) L62.

[5] O. Khaselev, J. Yahalom, J. Electrochem. Soc. 145 (1998) 190.

[6] O. Khaselev, D. Weiss, J. Yahalom, J. Electrochem. Soc. 146 (1999) 1757.

[7] F.A. Bonilla, A. Berkani, Y. Liu, P. Skeldon, G.E. Thompson, H. Habazaki, K. Shimizu, C. John, K. Stevens, J. Electrochem. Soc. 149 (2002) B4.

[8] A.Y. Simaranov, A.I. Marshakov, Y.N. Mikhailovskii, Protect. Met. 25 (1990) 611.

[9] D. Hawake, D.L. Albright, Met. Finish. 34 (October) (1995).

[10] M.A. González-Nuńez, P. Skeldon, G.E. Thompson, H. Karimzadeh, P. Lyon, T.E. Wilks, Corros. Sci. 37 (1995) 1763.

[11] M.A. González-Nuńez, P. Skeldon, G.E. Thompson, H. Karimzadeh, Corrosion 55 (1999) 1136. 
[12] A.L. Rudd, C.B. Breslin, F. Mansfeld, Corros. Sci. 42 (2000) 275.

[13] S. Ono, K. Asami, N. Masuko, Mater. Trans. JIM 42 (2001) 1225.

[14] H. Umehara, M. Takaya, Y. Kojima, Mater. Trans. JIM 42 (2001) 1691.

[15] M. Dabala, K. Brunelli, E. Napolitani, M. Magrini, Surf. Coat. Technol. 172 (2003) 227.

[16] Y. Xiang, W. Hu, X. Liu, C. Zhao, W. Ding, Trans. IMF 79 (2001) 30.

[17] K. Mori, H. Hirahara, Y. Oishi, H. Sasaki, Mater. Trans. JIM 42 (2001) 1219.

[18] A. Yamamoto, A. Watanabe, K. Sugahara, S. Fukumoto, H. Tsubakino, Mater. Trans. JIM 42 (2001) 1237.

[19] S. Fukumoto, A. Yamamoto, M. Terasawa, T. Mitamura, H. Tsubakino, Mater. Trans. JIM 42 (2001) 1232.

[20] I. Nakatsugawa, R. Martin, E.J. Knystautas, Corrosion 52 (1996) 921.

[21] M.G. Fontana, Corrosion Engineering, third ed., McGraw-Hill, New York, 1987, pp. 51-59.

[22] G. Song, A. Atrens, X. Wu, B. Zhang, Corros. Sci. 40 (1998) 1769.

[23] M. Pourbaix, Atlas of Electrochemical Equilibria in Aqueous Solutions, second ed., NACE, Houston, Texas, 1974, pp. 139-145, 475-484. 